Article

\title{
A Study on How the Five Senses Are Affected When Tourists Experience Towns with Forest Characteristics: An Empirical Analysis Based on the Data of Fujian, Guangdong and Sichuan in China
}

\author{
Min Shao ${ }^{1}$ and Derong Lin ${ }^{2, *}$ \\ 1 Beautiful Village Institute, Fuzhou Technology and Business University, Fuzhou 350715, China; \\ Graceminshao@163.com \\ 2 School of Management, Xiamen University, Xiamen 361005, China \\ * Correspondence: drlin65@xmu.edu.cn
}

\section{check for}

updates

Citation: Shao, M.; Lin, D. A Study on How the Five Senses Are Affected When Tourists Experience Towns with Forest Characteristics: An Empirical Analysis Based on the Data of Fujian, Guangdong and Sichuan in China. Sustainability 2021, 13, 8283. https://doi.org/10.3390/su13158283

Academic Editors: Naoum Tsolakis, Charisios Achillas and

Dimitrios Aidonis

Received: 13 June 2021

Accepted: 22 July 2021

Published: 24 July 2021

Publisher's Note: MDPI stays neutral with regard to jurisdictional claims in published maps and institutional affiliations.

Copyright: (c) 2021 by the authors. Licensee MDPI, Basel, Switzerland. This article is an open access article distributed under the terms and conditions of the Creative Commons Attribution (CC BY) license (https:// creativecommons.org/licenses/by/ $4.0 /)$.

\begin{abstract}
Senses are the primary channel by which travelers enjoy tourism, and the sensory experience of tourists is very important to the quality of their tourism experience. In this study, 385 questionnaires were distributed to tourists visiting the first batch of characteristic towns classified by the China National Forestry and Grassland Administration as national towns with forest characteristics. SPSS software was used for regression analysis to test the differences in the impact of sensory experience on the experience quality and future loyalty of forest town tourists. The results show that: (1) vision makes the highest contribution to the quality of tourist experience; (2) olfactory experience makes the lowest contribution to the quality of tourist experience and has no significant impact on it; (3) auditory experience has a significant impact on the quality of tourism experience but has no significant impact on the loyalty index. The study further confirms that, when a single sensory experience of tourists is insufficient, satisfaction can be achieved through the other senses. It is of great significance for forest town managers to design a sensory landscape according to the combined components of a destination's characteristics and the tourists' physical identities.
\end{abstract}

Keywords: five senses experience; tourism experience; experience quality; forest characteristic town

\section{Introduction}

The functional community of forest characteristic towns mainly depends on forest resources and ecological advantages, and organically combines "production, city, humanities and culture" [1]. Developing forest town tourism is conducive to further protecting forest biodiversity, transforming ecological advantages into development advantages, and realizing the combined development of environmental protection and the forest economy. However, at present, some small towns with forest characteristics have adopted imitative construction projects and practices [2,3]. Many towns look similar and have profound homogenization, which leads to a poor tourist experience and affects the income from tourism of these towns [4]. On this basis, some scholars have put forward the suggestion that the development of small towns with forest characteristics should highlight the original characteristics of towns, fully integrate regional culture, and maintain the originality of urban culture. Some scholars believe that we should start with the needs of tourists, emphasize the advantages of forest resources, and develop tourism products with forest characteristics [5], such as building experience projects related to forest resources to meet the physical and mental needs of tourists [6,7]. In 2018, the Blue Book of Forest Towns in China-Development Report of Forest Towns in China was jointly published by the China Forum for Development and the Social Science Literature Publishing House. It was mentioned that the planning of forest towns should incorporate the whole sensory experience, actively developing the ecological experience activities of perceiving, recognizing and experiencing 
nature, to improve the quality of tourists' experiences through sensory stimulation, thus promoting the sustainable development of forest towns. It can be seen that improving the tourists' experience will help enhance the heterogeneity of tourism development in small forest towns.

The tourism experience can be described as the interaction between tourists and destinations, with destinations being the places to be experienced, and tourists being participants in that experience [8]. As is different from traditional mass tourism, Poon puts forward the concept of "new tourism" and argues that experiential tourism focuses on tourists' natural and real experiences, so as to make tourism destinations more competitive, which lays a foundation for the development of tourism experience theory [9]. Tourism experience emphasizes the subjective evaluation of the tourists, who can evaluate tourist activities more intuitively through sight, hearing, smell, taste and touch, and, when all five senses interact with each other, this constitutes experience [10]. Studies have shown that enhancing the contribution of all five senses of tourists is helpful in promoting a positive travel experience. However, research on the sensory dimension of tourists' visiting experience mainly focuses on the influence of single senses, such as visual [11,12] and auditory senses [13], and on the tourists' perceptions, while ignoring the correlation effect between tourists' five senses and tourism experience [14]. However, the construction of a complete travel experience for tourists is realized through the participation of various senses, rather than from a single sensory stimulation [15]. At the same time, there is an interaction between the senses, and one sense cannot be separated from the other senses [16]. In recent years, research on tourism experience has emphasized the need to pay attention to the overall dimension of the five senses. According to the research results of Agapito and other scholars, Lv et al. established a model of "Senses-Experience Quality-Loyalty", which shows that the improvement of tourists' sensory experience helps to promote their positive experience quality, thus increasing the tourists' loyalty [17]. In addition, according to a survey of 241 tourists in Serra da Estrela Nature Park by Mateiro et al., although all senses are important, not all senses are equally important in terms of tourists' tourism experience [18]. At present, academic circles mainly analyze the importance of the five senses to the quality of tourists' experience $[19,20]$. As far as the impact on tourism experience is concerned, the differences among the five senses need further study [21]. When the five senses' experience has an overall positive impact on the quality of the tourists' experience, does it suggest that each sensory experience has a positive effect on the quality of the tourists' experience? If so, what are the impacts of five sensory experiences on the quality of the tourism experience for tourists in small forest towns?

In view of this, based on the perspective of tourism experience and the model of "Senses-Experience Quality-Loyalty", regression analysis is used to explore the differences of the influence of the five sensory experiences on the tourism experience in small forest towns, in order to provide important reference data for the landscape planning of small towns with forest characteristics.

\section{Theoretical Basis and Research Hypothesis}

\subsection{Tourism Experience and the Five Senses Experience}

The term "experience" was put forward by the American economist Alvin Toffler, who mainly studied the consumers' experience of consumption and its economic value. Toward the end of the 1990s, Pine and Gilmore put forward the concept of the "experience economy", arguing that experience can create an unforgettable memory for consumers. Tourism experience is a part of consumer experience, and experience is the essence of tourism activities. Therefore, tourism has become a pioneer in the era of the experience economy [22]. However, the academic research on tourism experience mainly begins with the debate on "Reality" by western scholars. Boostin thinks that tourism experience activities for tourists are regarded as pseudo-events [23]. However, this view has been challenged. MacCannell believes that, although tourists have a short experience, they are 
still eager to see the daily life of local people and get along with them [24]. Compared with these two viewpoints, Cohen's viewpoint is more neutral, emphasizing that tourism experience varies from person to person [25]. According to whether an individual is attached to a certain spiritual "center", from the phenomenological point of view, the tourist experience modes are divided into five types: entertainment type, pastime type, and so on.

However, Professor Xie, a scholar in and of China, believes that the tourism experience is a sort of comfortable feeling of physical and mental integration when tourists are deeply integrated with their current situation [26]. In other words, the tourist experience is not static. With a change of time and place, the personal cognition and emotion of the same tourist will be different. Tourists construct their own tourism experience in specific tourism locations, and form various interactions between people and things [27]. Therefore, tourism experience connects the tourism subject, tourism object and media, and is influenced by factors such as the tourists' emotions and motivations, scenic spots, other tourists and local residents [28]. In recent years, Fan Mengyou and other scholars have emphasized that tourism experience research should return to tourists as the main subject, and they think that tourism experience is mainly the cognitive and emotional experience gained through the specific physical feelings of tourists [29].

As the carrier of tourism experience [30,31], physical feeling is an important dimension by which to measure consumer experience. Previously, Urry advocated that the tourism experience is essentially a special gaze. Within a specific time-space relationship, the tourism gaze can bring tourists a pleasant travel experience [32]. Therefore, visual centralism has become the earliest and most fruitful aspect in the sensory study of the tourism experience. With the deepening of tourism experience research, Urry and other scholars believe that tourism experience includes various sensory experiences, such as hearing, smell, taste and touch, besides merely visual consumption $[33,34]$. This understanding is consistent with the current mainstream view in tourism academia, and the tourism experience is multisensory and obtained through tourists' physical perceptions [29]. Customer's thinking reaction caused by visual, auditory, tactile, olfactory and gustatory stimuli is regarded as a sensory experience.

Schmitt thinks that the sensory experience is the most direct and impressionable experience for customers, which can trigger consumers to have a positive experience through visual, auditory, tactile, olfactory and gustatory stimuli [35]. Current research has confirmed that stimulating consumers' five senses can improve their overall experience quality [36]. Tourists' perceptions of a destination mainly come from sensory input and sources a variety of sensory experiences. Stimulation activates the senses, so that each tourist's cognition, emotion and destination experience are connected, thus affecting the quality of the overall tourism experience [37]. Therefore, enhancing the overall contribution of the tourists' five senses is helpful to promote a positive tourism experience. In addition, studies also found that enhancing the sensory diversity of tourist destinations can also help tourists to form unforgettable tourism experiences [20,38]. A tourist destination attracts tourists not only with visual elements but also with other senses, which are related to the construction of a sensory-oriented landscape [39]. Pan and Ryan found that when the destination scene caters to all the senses of tourists, it can enrich the visitor experience of tourists [40].

\subsection{Five Senses Experience and Loyalty}

The concept of loyalty, in the marketing field, is used to study the customer's commitment to buying a certain product or service repeatedly [41]. Loyalty is multidimensional, including cognitive loyalty, emotional loyalty, attitude loyalty and action loyalty. Krishna believes that stimulating consumers' senses can influence their perception, judgment and behavior [42]. The influence of the five senses' experience on consumers' behavioral intention has been proved many times in the field of marketing. In recent years, tourism scholars have pointed out that tourist loyalty is not only affected by the perceived quality [43] and 
value of a destination's image [44], but also by sensory impressions [45]. When tourists choose destinations, the choices are based on rational evaluation or intuitive responses based on physical attributes. The richer the sensory experience, the stronger the tourists willingness to revisit in the future. Empirical research shows that a diversity of sensory impressions is helpful for tourists to form long-term memories, thus encouraging tourists to have effective behaviors of revisiting those destinations [46]. At the same time, it can influence the judgment of tourists' future behavior through sensory cues of different forms, like visual cues [47], such as photos, auditory cues [13] and music. In addition, other sensory information, such as the sense of touch, smell [48] and taste [49], can also influence tourists' decisions to revisit destinations.

Therefore, the following hypothesis and secondary hypotheses are proposed:

Hypothesis 1 (H1). A five senses experience has a significant positive impact on loyalty.

Hypothesis 1 (H1a). Visual experience has a significant positive impact on loyalty.

Hypothesis 1 (H1b). Auditory experience has a significant positive impact on loyalty.

Hypothesis 1 (H1c). Olfactory experience has a significant positive impact on loyalty.

Hypothesis 1 (H1d). Taste experience has a significant positive impact on loyalty.

Hypothesis 1 (H1e). Tactile experience has a significant positive impact on loyalty.

\subsection{The Mediating Role of Experience Quality}

According to the theory of tourism experience, the purpose of the tourism experience is to pursue pleasure $[50,51]$. Researchers often use satisfaction to express the quality of the tourism experience [52,53]. In previous studies, the quality of an experience was normally used as the mediating variable of a destination's image [54-56], affecting tourists' loyalty. However, tourists can evaluate their destinations through visual and auditory senses, which will affect their perceived quality and satisfaction, which then affects their behavioral intentions [57]. Lv et al. think that, compared with the abstract destination image, the sensory impression of a travel experience has an increased explanatory power to stimulate tourists' future behavioral intentions. The empirical study found that when the tourists' five senses experience is diverse and positive, the quality of the tourists experience will be improved, thus enhancing their loyalty. Experience quality is regarded as the mediating variable regarding the influence of sensory impressions on tourists' loyalty. Ding created a five senses design of tourism products (tourism vehicles) and found that mobilizing tourists' five senses can bring them pleasure [58]. Compared with other dimensions of experience, the tourists' sensory experience has the greatest influence on satisfaction [59]. At the same time, the quality of the tourism experience directly affects the loyalty of tourists $[60,61]$.

Therefore, the following hypotheses and secondary hypotheses are proposed:

Hypothesis 2 (H2). Five sense experience has a significant positive impact on experience quality.

Hypothesis 2 (H2a). Visual experience has a significant positive impact on experience quality.

Hypothesis 2 (H2b). Auditory experience has a significant positive impact on experience quality.

Hypothesis 2 (H2c). Olfactory experience has a significant positive impact on the quality of the experience.

Hypothesis 2 (H2d). Taste experience has a significant positive impact on experience quality. 
Hypothesis 2 (H2e). Tactile experience has a significant positive impact on experience quality.

Hypothesis 3 (H3). Experience quality plays a significant mediating role between five senses experience and loyalty.

According to the hypotheses, we have constructed a hypothetical structure path diagram (Figure 1).

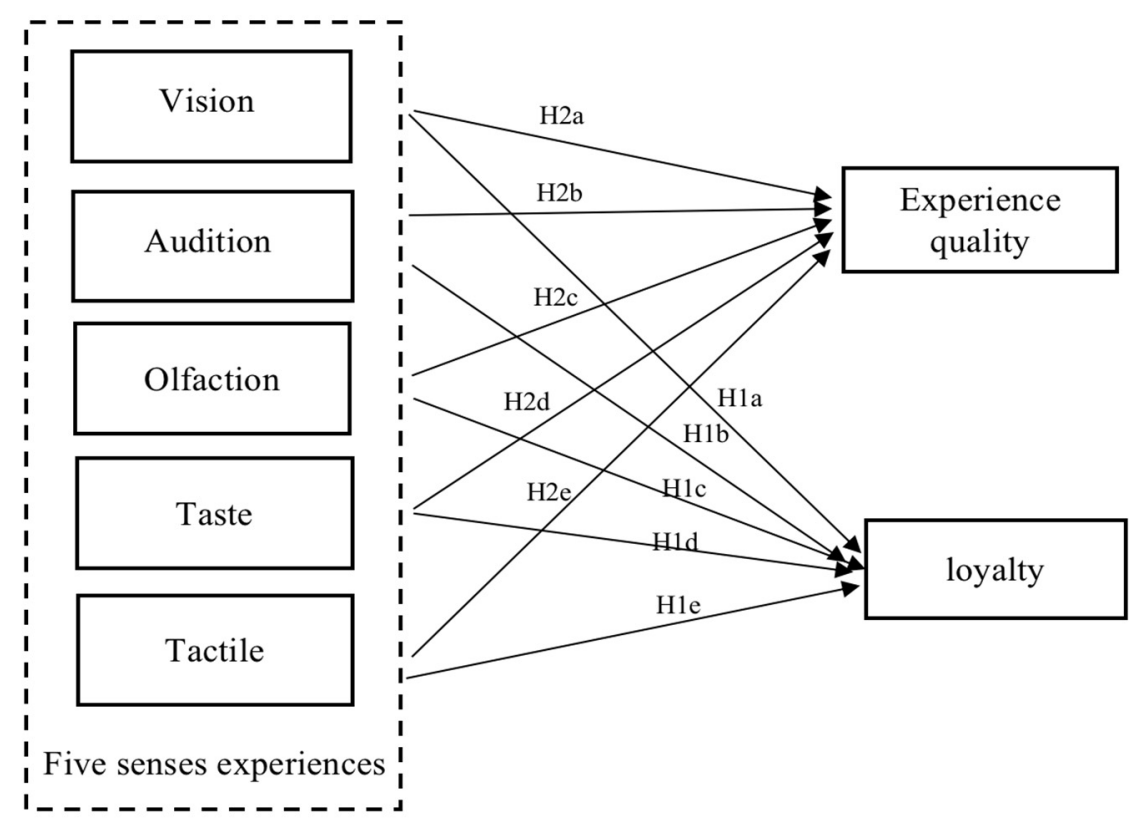

Figure 1. Hypothetical structure path diagram.

\section{Data Collection and Model Building}

\subsection{Questionnaire Design}

In order to ensure the scientific and strict setting of questionnaire indicators, the questionnaire was modified by using a maturity scale as a reference. The research team conducted a questionnaire pre-test in early November 2019. According to the forecast results, some questionnaire items were adjusted to generate formal questionnaires. The research framework of the questionnaire consists of two parts: the first part comprises three key variable scales, including five sensory experiences, experience quality and loyalty, with a total of 30 items that are measured by a Likert five-point scale. The second part comprises the social and demographic characteristics, including six items such as gender, age and place of residence.

The five sensory experience indexes mainly come from the sensory impression items scale of Lv et al. [17]. Because the forest town is mainly located in the suburbs and occupies a quiet ecological landscape, items such as "nightlife", "noise", "fish treatment center", and "car washing service" are deleted from our version of the original scale. At the same time, small towns with forest characteristics have high forest coverage, and the forest releases natural aromas, such as from flowers and plants. Therefore, the item "smell of plants" was added in the sense of smell category, which made the scale more suitable for forest characteristic towns. To sum up, the five sensory experiences are divided into five dimensions: visual experience, auditory experience, tactile experience, olfactory experience, and taste experience, among which vision includes ten items, such as architecture and scenery. Hearing includes three items, including quiet sounds and water sounds. Touch includes five items, such as water on the body and coolness, whereas smell includes three items, such as fresh air and flowers, and taste includes three items like local foods and fruit.

The experience quality indicator mainly draws on the Fornell scale [62], and uses the three items for the satisfaction variable in the ACSI model as the evaluation indicators 
of experience quality, such as the overall experience satisfaction, the actual experience compared with the ideal scenic spot, etc.

The loyalty indicator adopts that of Wang Xia and other scales [63], including 3 items such as a willingness to recommend, and a willingness to revisit.

\subsection{Data Collection}

In this study, the first batch of towns identified as national forest towns in China (Sichuan Province, Guangdong Province and Fujian Province) were selected for investigation. Fujian Province and Guangdong Province have high forest coverage rates, ranking first and sixth respectively in the forest coverage rate rankings of China's provinces. The development of forest towns in these two provinces have unique resource endowments and are representative, to some extent. However, the development of forest towns in Sichuan Province has been valued and vigorously promoted by local authorities, among which 16 forest towns have been rated as the most beautiful forest towns in China ( 25 have been identified as the most beautiful forest towns in China at present), making them the first choice for tourists.

Based on this, the research group members conducted a four-month field investigation in the Great Lakes forest town of Yongtai in Fujian Province, from May to September in 2019. Yongtai Great Lakes forest town is located in the east of Yongtai County, in Fuzhou City in Fujian Province. Yongtai Great Lakes forest town is centered around the Fujian Great Lakes State-owned Forest Farm, from which radiate Danyun Town, Geling Town, and Chengfeng Town, etc. The planned total area is 8133.3 hectares, and the forest coverage rate of the town is over $80 \%$.

In December 2019, the research group members went to the forest town of Shawan, in Guangzhou, where the planning and construction of the forest town were relatively mature, and distributed 88 questionnaires to tourists. Guangzhou's Shawan forest town is located in the hinterland of the Pearl River Delta in China, and in the west of Panyu District in Guangzhou City of the Guangdong Province. Guangzhou's Shawan forest town includes Shawan Ancient Town, Dripping Rock Forest Park and other areas belonging to the forest town of Lingnan Water.

In addition, from November to December 2019, the research group used questionnaires to carry out online research work. Assisted by teachers from the Sichuan Tourism College, Sichuan Mianyang Normal University, Guangzhou Ecological Engineering Vocational College, Fujian Agriculture and Forestry University, online questionnaires were distributed to tourists who had visited forest towns in Sichuan Province, Guangdong Province and Fujian Province. In order to ensure that the respondents had previous tourism experience in forest towns, a screening condition is set in the first item of the questionnaire: "Have you ever visited a forest town? Select "Yes" to continue answering and select "No" to finish answering". 326 online questionnaires were collected. There were 414 online and offline surveys, of which 29 invalid questionnaires were excluded, producing an effective rate of $93 \%$.

\subsection{Test of Reliability and Validity of Scale}

The reliability and validity of the questionnaire results were tested. The total Cronbach's alpha coefficient of the scale was 0.944 , which was higher than the standard of 0.7 , indicating that the internal consistency of the measurement indicators was good. The construction of the scale is based on other mature questionnaires, which gives good content validity. The KMO statistical value of the scale is 0.759 , and the $p$-value of Bartlett's spherical test is less than 0.001 , which shows that it has statistical significance and good structural effectiveness.

\subsection{Construction of an Econometric Model}

Considering the different motivations of each person, especially the sensory barriers faced by some people, five-sensory factors should be integrated into tourism destination 
planning, including vision, hearing, smell, taste and touch. In order to provide empirical support for the planning of an effective destination strategy, the regression method is used to explore the impact of the five senses on quality and loyalty.

Firstly, the regression equations of five senses and loyalty, five senses and quality, and quality and loyalty are established, respectively, as shown in Equations (1)-(3).

$$
\begin{aligned}
& Y=\alpha_{0}+\alpha_{i} X_{i}+\varepsilon_{1} \\
& Z=\beta_{0}+\beta_{i} X_{j}+\varepsilon_{2} \\
& Y=\gamma_{0}+\gamma_{i} Z_{k}+\varepsilon_{3}
\end{aligned}
$$

Among them, $Y$ represents loyalty, $X$ represents the five senses and $Z$ represents experience quality, while $\alpha_{0}, \beta_{0}$, and $\gamma_{0}$ represent constant terms, $\alpha_{i}, \beta_{i}$, and $\gamma_{i}$ represent the variable coefficients, and $\varepsilon_{1}, \varepsilon_{2}$, and $\varepsilon_{3}$ represent the error terms.

Secondly, the regression equation is established for the relationship between the five senses of vision, hearing, smell, taste and touch, with respect to loyalty, Then, the regression equation is established for the relationship between the five senses of vision, hearing, smell, taste and touch, with respect to quality, as shown in Equations (4) and (5), respectively.

$$
\begin{gathered}
Y=\lambda_{0}+\sum_{l=1}^{5} \sigma_{l} x_{l}+\delta \\
Z=\kappa_{0}+\sum_{m=1}^{5} \eta_{m} x_{m}+\varepsilon
\end{gathered}
$$

Among these, $l=1, \ldots, 5$ and $m=1, \ldots, 5$, the five senses are visual, auditory, olfactory, taste and tactile.

\section{Results Analysis}

\subsection{Analysis of the Basic Situation of the Sample}

There were 385 points of valid data in this survey questionnaire, and the age distribution of respondents was normal. The respondents under 17 years old account for $7.27 \%$, those aged 18-25 account for $38.96 \%$, those aged $26-44$ account for $34.81 \%$, those aged $45-59$ account for $16.36 \%$, and those over 60 account for $2.6 \%$. The respondents' academic qualifications are mostly college and undergraduate, accounting for $61.56 \%$, with junior high school and above accounting for $10.39 \%$, high school, technical secondary school and vocational high school accounting for $14.55 \%$, and graduate students and above accounting for $13.51 \%$. In terms of occupation, students account for $31.43 \%$, followed by professional technicians (doctors, teachers, etc.) accounting for $23.12 \%$, company employees accounting for $16.36 \%$, civil servants, private owners, farmers, freelancers and retirees accounting for $4.68 \%, 3.12 \%, 3.12 \%, 6.75 \%$ and $2.60 \%$ of the total number, respectively. In terms of family monthly income, the monthly income is 3001-6000 yuan, accounting for $29.87 \%$, and 6001 yuan and up, accounting for 21.30. The number of respondents whose monthly income is 1001-3000 yuan or higher than 6000 yuan is relatively small, accounting for $12.99 \%$ and $7.53 \%$, respectively (see Table 1 ). 
Table 1. Basic status of the samples $(\mathrm{N}=385)$.

\begin{tabular}{|c|c|c|c|c|c|c|c|}
\hline Index & Option & Quantity & Percentage $\%$ & Index & Option & Quantity & Percentage $\%$ \\
\hline \multirow{4}{*}{ Gender } & \multirow[t]{2}{*}{ Male } & \multirow[t]{2}{*}{205} & \multirow[t]{2}{*}{53.25} & \multirow{4}{*}{ Education } & $\begin{array}{l}\text { Junior high school and } \\
\text { below }\end{array}$ & 40 & 10.39 \\
\hline & & & & & $\begin{array}{l}\text { High school, technical } \\
\text { secondary school and } \\
\text { vocational high school }\end{array}$ & 56 & 14.55 \\
\hline & \multirow{2}{*}{ Female } & \multirow{2}{*}{180} & \multirow{2}{*}{46.75} & & $\begin{array}{c}\text { College and } \\
\text { undergraduate }\end{array}$ & 237 & 61.56 \\
\hline & & & & & Postgraduate and above & 52 & 13.51 \\
\hline \multirow{5}{*}{ Age } & $<17$ years & 28 & 7.27 & \multirow{9}{*}{ Profession } & Civil servant & 18 & 4.68 \\
\hline & $18-25$ years & 150 & 38.96 & & White-collar worker & 63 & 16.36 \\
\hline & 26-44 years & 134 & 34.81 & & Private owners & 12 & 3.12 \\
\hline & $45-59$ years & 63 & 16.36 & & Farmer & 12 & 3.12 \\
\hline & $>60$ years & 10 & 2.60 & & Student & 121 & 31.43 \\
\hline \multirow{9}{*}{ Origin } & Northeast China & 6 & 1.56 & & $\begin{array}{l}\text { Professional skilled } \\
\text { worker }\end{array}$ & 89 & 23.12 \\
\hline & North China & 15 & 3.90 & & Freelance & 26 & 6.75 \\
\hline & Northwest China & 5 & 1.30 & & Retirees & 10 & 2.60 \\
\hline & South-west China & 62 & 16.10 & & other & 34 & 8.83 \\
\hline & South China & 157 & 40.78 & \multirow{5}{*}{ Income } & $\leq 1000$ Yuan & 109 & 28.31 \\
\hline & Central China & 23 & 5.97 & & $1001-3000$ Yuan & 50 & 12.99 \\
\hline & East China & 110 & 28.57 & & 3001-6000 Yuan & 115 & 29.87 \\
\hline & $\begin{array}{l}\text { Hong Kong, Macau } \\
\text { and Taiwan }\end{array}$ & 3 & 0.80 & & 6001 Yuan and over & 82 & 21.30 \\
\hline & other & 4 & 1.02 & & $\geq$ Yuan & 29 & 7.53 \\
\hline
\end{tabular}

\subsection{Analysis of the Impact of Tourists' Five Senses Experience on Loyalty}

4.2.1. Descriptive Statistics and Related Analysis

After sorting and analyzing the average value, standard deviation, and correlation matrix of each variable (see Table 2), the correlation analysis shows that the five senses experience, experience quality, and loyalty are significantly positively correlated.

Table 2. Descriptive statistics and correlation analysis of each variable.

\begin{tabular}{cccccc}
\hline Variable & $\mathbf{M}$ & SD & $\mathbf{1}$ & $\mathbf{2}$ & $\mathbf{3}$ \\
\hline $\begin{array}{c}\text { Quality of } \\
\text { experience }(Z)\end{array}$ & 3.625 & 0.998 & 1 & $0.896^{* *}$ & $0.822^{* *}$ \\
$\begin{array}{l}\text { Loyalty }(Y) \\
\begin{array}{c}\text { Five senses } \\
\text { experience }(X)\end{array}\end{array}$ & 3.679 & 1.121 & $0.896^{* *}$ & 1 & $0.834^{* *}$ \\
Note: M: Median, SD: Standard deviation; **: $p<0.01$, as below. & $0.822^{* *}$ & $0.834^{* *}$ & 1 \\
\hline
\end{tabular}

Note: M: Median, SD: Standard deviation; ${ }^{* *}: p<0.01$, as below.

\subsubsection{Mediating Effect Test}

We examined the way that tourists' five senses experience affects loyalty and discussed whether it has a direct impact. We studied the mediating effect of tourists' experience quality between five senses experience and loyalty, according to the mediating effect test procedure put forward by Wen Zhonglin [64]. Three-step regression analysis was used to analyze the data: Equation (1) analyzed the influence of five senses experience on loyalty; Equation (2) analyzed the influence of five senses experience on experience quality; Equation (3) analyzed the influence of five senses experience and experience quality on loyalty.

It can be seen from the results in Table 3 that, on the whole, the F-tests of the three regression models are all significant at a significance level of 0.001 , and the fitting coefficients of the models are all above $67 \%$, indicating that the models have a good fit and are suitable for data analysis. In the first-step regression model, the five senses experience has a significant positive impact on loyalty, and the standardized regression coefficient is 0.927 , so hypothesis $\mathrm{H} 1$ passes the test. In the second-step regression model, the five 
senses experience has a significant positive impact on the quality of experience, and the regression coefficient is 0.814 , therefore, hypothesis $\mathrm{H} 2$ passes the test. On the basis of the first step, tourists' experience quality is introduced for the third step regression analysis. The results show that both the experience quality and five senses experience significantly affect loyalty, at a significance level of 0.001 . The standardized regression coefficient of experience quality to loyalty is 0.732 , and that of five senses experience to loyalty is 0.331 . After the introduction of experience quality, the influence of five senses experience on loyalty is still significant, but the standardized regression coefficient decreases noticeably, which indicates that experience quality plays a partial mediating role in the relationship between five senses experience and loyalty. Thus, hypothesis $\mathrm{H} 3$ passes the test.

Table 3. The mediating effect test of tourist experience quality.

\begin{tabular}{|c|c|c|c|c|c|c|}
\hline \multirow{3}{*}{ Variable } & \multirow{2}{*}{\multicolumn{2}{|c|}{$\begin{array}{c}\text { Equation (1) } \\
\text { Loyalty }(Y)\end{array}$}} & \multicolumn{2}{|c|}{ Equation (2) } & \multicolumn{2}{|c|}{ Equation (3) } \\
\hline & & & \multicolumn{2}{|c|}{ Quality of Experience (Z) } & \multicolumn{2}{|c|}{ Loyalty (Y) } \\
\hline & $\beta$ & $\mathbf{t}$ & $\beta$ & $\mathbf{t}$ & $\beta$ & $\mathbf{t}$ \\
\hline $\begin{array}{c}\text { Five sense } \\
\text { experience }(X)\end{array}$ & 0.927 & $29.525^{* * *}$ & 0.814 & $28.264^{* * *}$ & 0.331 & $8.094^{* * *}$ \\
\hline $\begin{array}{l}\text { Quality of } \\
\text { experience }(Z)\end{array}$ & - & - & - & - & 0.732 & $17.698^{* * *}$ \\
\hline F value & \multicolumn{2}{|c|}{$871.701^{* * *}$} & \multicolumn{2}{|c|}{$798.843^{* * *}$} & \multicolumn{2}{|c|}{$947.766^{* * *}$} \\
\hline $\mathrm{R}^{2}$ & \multicolumn{2}{|c|}{0.694} & \multicolumn{2}{|c|}{0.675} & \multicolumn{2}{|c|}{0.831} \\
\hline
\end{tabular}

\subsection{Analysis of the Impact of Five Sense Experience on Experience Quality and Loyalty}

We further examined the concrete influence of five sensory experiences on quality of experience and loyalty. The results in Table 4 show that the five senses experience can explain $68.8 \%$ variance of experience quality and $70.4 \%$ variance of loyalty. The results of the $\mathrm{F}$ value show that the $p$-values of the two models are significant, at a significance level of 0.001 , and the models can be used for data analysis after the statistical test. According to the $\mathrm{T}$ values of different variables, hypotheses $\mathrm{H} 2 \mathrm{a}, \mathrm{H} 2 \mathrm{~b}, \mathrm{H} 2 \mathrm{c}, \mathrm{H} 2 \mathrm{e}, \mathrm{H} 1 \mathrm{a}, \mathrm{H} 1 \mathrm{c}$ and H1e are verified, while $\mathrm{H} 2 \mathrm{~d}, \mathrm{H} 1 \mathrm{~b}$ and $\mathrm{H} 1 \mathrm{~d}$ failed the test.

Table 4. Regression analysis of tourist's five sense experience on experience quality and loyalty.

\begin{tabular}{ccccc}
\hline \multirow{2}{*}{ Variable } & \multicolumn{2}{c}{ Quality of Experience $(Z)$} & \multicolumn{2}{c}{ Loyalty $(\mathbf{Y})$} \\
\cline { 2 - 5 } & $\boldsymbol{\beta}$ & $\mathbf{t}$ & $\boldsymbol{\beta}$ & $\mathbf{t}$ \\
\hline Vision $\left(x_{1}\right)$ & 0.387 & $5.078^{* * *}$ & 0.367 & $4.956^{* * *}$ \\
Audition $\left(x_{2}\right)$ & 0.161 & $2.312^{*}$ & 0.06 & 0.884 \\
Olfaction $\left(x_{3}\right)$ & -0.016 & -0.223 & 0.064 & 0.927 \\
Taste $\left(x_{4}\right)$ & 0.156 & $2.748^{* *}$ & 0.18 & $3.258^{* *}$ \\
Tactile $\left(x_{5}\right)$ & 0.187 & $2.49^{*}$ & 0.215 & $2.941^{* *}$ \\
F value & \multicolumn{3}{c}{$167.202^{* * *}$} \\
$\mathrm{R}^{2}$ & 0.688 & \multicolumn{3}{c}{0.704} \\
Note: $: p<0.05^{* * *}: p<0.01^{* * *}: p<0.001$, as below.
\end{tabular}

\subsubsection{Analysis of the Impact of the Five Senses on Tourists' Loyalty}

The coefficients of visual experience are 0.367 , which are significant at the level of 0.001 , and the $\mathrm{T}$ value is 4.956 . The coefficients of taste experience and tactile experience are 0.18 and 0.215 , respectively, which are significant at the level of 0.01 , and the T values are 3.258 and 2.941, respectively, indicating that tourists' visual experience, taste experience and tactile experience have significant positive effects on their loyalty. It is proved that $\mathrm{H} 1 \mathrm{a}, \mathrm{H1c}$ and H1e pass the test. The results show that a good visual experience not only makes tourists form a positive quality of tourism experience, but also encourages tourists to recommend and revisit the forest town. At the same time, a positive taste experience can 
be the driving force for visitors to revisit their destinations. However, tactile experience is different from visual and auditory experience, and visitors need to be in the forest town to experience it. Emotional contact in tactile experience is an important driving force for tourists to make decisions on revisiting destinations after traveling.

The coefficients of auditory experience and olfactory experience are 0.06 and 0.064 , respectively, which are not significant at the level of 0.05 , and the $T$ values are 0.884 and 0.927, indicating that the auditory experience and olfactory experience of tourists have no significant impact on their loyalty. It is, thus, shown that H1b and H1d fail the test. Previous studies have shown that although soundscape is an important aspect of tourists' experience, tourists seldom consider soundscape elements when choosing destinations [65]. Therefore, auditory experience is not a driving factor for tourists' loyalty to forest towns. At the same time, an experiment by Lwin found that environmental odor is a weaker memory trigger than product odor, which is not conducive to creating consumers' long-term memory [66]. Memory is at the core of tourism experience; Agapito et al. believe that long-term memory is an important indicator to predict whether tourists will revisit the site. Therefore, the olfactory experience did not increase the tourists' willingness to revisit the forest town.

\subsubsection{Analysis of the Impact of the Five Senses on Tourists' Experience Quality}

The visual experience coefficient is 0.387 , which is significant at the level of 0.001 , and the $\mathrm{T}$ value is 5.078 , indicating that tourists' visual experience has a very significant positive effect on their experience quality, indicating that hypothesis H2a passes the test. Vision is the first in importance of the senses [14]. People mainly process information through visual communication. The natural ecosystem in the forest characteristic town area is stable, with the characteristics of high forest coverage and unique forest vegetation. With seasonal changes, climate changes, and differences in plant community composition and growth, different forest colors are formed that have an impact on people's vision. From the visual point of view, the forest is mainly green, and the green color gives people associations such as vitality and environmental protection. Therefore, green plays a positive role in regulating emotions [67]. In addition to forest vegetation, rare and endangered animals, village buildings and guidance systems in small towns with forest characteristics can also stimulate visitors to have a profound visual impression. In recent years, some scholars have pointed out that tourism products dominated by vision will lead to tourists' visual fatigue [68], but from the results of this study, vision is still the dominant sense for tourists' tourism experience, and the visual landscape has a high contribution to the positive tourism experience quality of tourists in forest towns. Therefore, destination managers should pay attention to the influence of visual experience on the quality of tourists' tourism experience and treat the visual landscape as an important element in the planning of forest towns. Actively creating pleasant visual experiences before and during the different stages of tourism will further enhance the experience quality of tourists in forest towns.

The coefficient of auditory experience is 0.161 , which is significant at the level of 0.05 , and the T value is 2.312, which shows that tourists' auditory experience has a significant positive effect on their experience quality, indicating that hypothesis $\mathrm{H} 2 \mathrm{~b}$ passes the test. The auditory landscape is often matched with the abovementioned visual landscape. Some studies have pointed out that the acoustic environment of the destination plays a key role in promoting tourists' active travel experience [65]. As far as tourists in small towns with forest characteristics are concerned, natural sounds such as birds singing and mountain streams, or the quiet acoustic environment in villages, meet tourists' cognition and expectations of the sound scene, and a natural sound scene also helps to stimulate tourists' hearing, which makes people feel happy. According to the theory of tourism experience, high-quality tourism experiences satisfy tourists' expectations or even exceed them [69]. In short, when tourism expectations are consistent with actual tourism activities, it will help tourists make a positive evaluation regarding the quality of the tourism experience. From the research results, it can be seen that when a certain sensory experience of tourists does not exceed 
their travel expectations, as long as it meets the sensory recognition of the symbolic value of the destination, tourists will still enjoy a positive and quality experience.

The olfactory experience coefficient is -0.016 , which is not significant at the level of 0.05 , and the $T$ value is -0.223 , indicating that the olfactory experience of tourists has no significant impact on their experience quality, which means that hypothesis $\mathrm{H} 2 \mathrm{~d}$ fails the test. Compared with the other senses, olfactory experience is easily overlooked. Among the tourist attractions in forest towns, the forest can release the fragrance of flowers and plants, the fragrance of soil, and the special substance Fendozin. The fragrance released by plants has certain effects on improving human health [70]. Among them, Fendozin is known as phytoncide. Studies have shown that forest Fendozin aromatherapy can effectively kill or inhibit human germs [71]. However, in the actual investigation, it is found that tourists in small towns with forest characteristics generally ignore the smell perspective of forests and villages. Therefore, in tourism publicity, destination managers should highlight the role of plant odor in improving human health, increase tourists' attention to the olfactory experience of forest towns, and promote their experience value. With the change of life-cycle stages of forest characteristic towns, managers should not neglect the maintenance of tourist facilities and landscapes, so as to avoid a negative impact on tourists' olfactory experience.

The taste experience coefficient is 0.156 , which is significant at the level of 0.01 , and the $\mathrm{T}$ value is 2.748 , which indicates that the taste experience of tourists has a significantly positive effect on their experience quality, showing that hypothesis H2e passes the test. Sima Qian wrote, in the Biography of Lu Jia, in Historical Records: "The king regards the people as heaven, while the people regard food as heaven". This shows the importance of food to people's daily life. Chang et al. suggest that traveling and dining is a pleasant sensory experience, and food has become an indispensable travel experience for tourists in their travel activities [72]. Tasting local delicacies in forest towns requires tourists' physical participation. Whether destination delicacies are the main motivation of tourists or not, delicacies can provide unforgettable travel experiences for tourists. Quan et al. believe that peak experience and auxiliary experience together constitute a complete tourist experience. Under certain conditions, food is not only an auxiliary experience in tourists' travel experience; a positive taste experience can arouse tourists' peak experience [22]. Food provides a perspective for tourists to understand the tourism destination culture [73], which means that when tourists in forest towns have a positive taste experience, they can get closer to the destination culture of forest towns, producing a sense of closeness, and further enhancing the quality of tourism experience.

The coefficient of tactile experience is 0.187 , which is significant at the level of 0.05 , and the $\mathrm{T}$ value is 2.49 , which indicates that tourists' tactile experience has a significant positive effect on their experience quality, indicating that hypothesis $\mathrm{H} 2 \mathrm{c}$ passes the test. Touch is often closely related to outdoor experience activities. Soft soil, the handrails of trails, guide signs, tables and chairs in rest areas, and other objects can bring a more profound experience to forest town tourists, and keep the tourists close to the forest town. However, the polluted water and sticky rocks greatly reduce tourists' tactile pleasure [74]. In addition, different emotions and forms of touch will have different influences on consumers' behavior [75], such as the emotional contact between tourists and forest town residents. When tourists choose accommodation facilities, they will not only consider safety, hygiene, price, and other factors, but also desire to interact with forest town residents and experience local life and folk customs deeply. The emotional experience of host-guest interaction has a direct impact on tourists' experience quality [76,77]. Therefore, creating tactile experience should not only pay attention to the construction of tourism facilities and other service landscapes in forest town destinations but also pay attention to community residents among forest town stakeholders and encourage community residents to actively participate in tourism reception activities in forest town destinations. 


\section{Research Conclusions and Prospects}

\subsection{Conclusions}

The purpose of this study is to explore the differences in the influence of various sensory experiences on the quality and loyalty of the tourists' tourism experience, by establishing a regression model. The findings of this study are as follows. First, the results show that auditory senses have a positive and significant impact on the quality of the tourists' experience. This is consistent with the viewpoint raised by Liu et al. that a "sound scene can improve tourists' satisfaction". However, although a positive auditory experience can effectively improve the experience quality of tourists [78], auditory stimuli have no significant effect on loyalty. This study verifies that satisfaction cannot completely lead to consumer loyalty behavior, and further explains the reason why Xingyang Lv et al. mentioned that "sensory impression only partially mediates the interpretation of loyalty" [21]; Second, although the olfactory senses have no significant impact on the quality and loyalty of the tourism experience, the overall experience of the five senses of tourists in forest towns has a significant impact on their quality and loyalty. That is to say, when tourists are physically and mentally integrated into a positive tourism experience, not one of the five sensory stimuli ranks higher than their own sensory experience threshold. It can be deduced that when one or several sensory experiences are insufficient, it is also possible to have a pleasant tourism experience. At the same time, the tourism experience itself needs to consider the barrier-free experience of tourists, including hearing, vision, etc. [79]. It should be noted that for the disabled, tourism is a multi-sensory physical experience [80]. The travel experience of tourists with sensory impairments is a concern. For example, when a visually impaired person travels, although there is no visual stimulation, hearing, smell, taste and touch can still stimulate the overall tourism experience [81]. The research suggests that when tourists have an insufficient sensory experience, they can make sensory compensation by stimulating other senses, so as to enhance their experience, which gives an answer to the research of Zhong et al. which mentioned "how to make sensory compensation" [82]. Therefore, through regression analysis, this study found that, compared with the single sensory experience perspective, it is more reasonable to study the influence of the comprehensive five senses experience on the quality of the overall tourism experience.

\subsection{Suggestion}

First, the tourists' experience is the key element of the sustainable development of tourism destinations. The managers of tourism destinations should eliminate any negative sensory elements in the landscape, thus contributing to the green and sustainable development of these tourism destinations. This will avoid negatively affecting the quality of the tourists' experience and will increase their willingness to revisit. For example, in view of the tourists' lack of olfactory sensory experience, managers should promote the health care benefits of Fendozin and, in time, popularize the functions of forest health care products to the public, and raise tourists' awareness of olfactory experience in forest towns. At the same time, managers should pay attention to the visual esthetic needs of tourists, paying attention to the activation of the forest landscape, water purification, etc., in order to prevent tourists from having negative sensory experiences.

Second, in the design of the destination landscape, due to the diversity of tourists' travel motives, managers can plan and market from an overall five senses perspective according to the characteristics of the destination. Sensory compensation can not only further enhance the quality of the tourism experience, but also arouse the positive tourism experience of tourists with sensory impairments, thus creating destinations for sensorychallenged tourists. It is important to pay attention to tourists' demands for the multisensory interactive experience of landscape design and enhance tourists' travel experience. For example, the use of video, pictures, live broadcasts, and various other publicity methods can stimulate tourists' visual and auditory feelings and attract potential tourists to the small forest towns, and in addition, strengthening the connection between destination products and tourists' five sensory experiences. For example, in view of tourists' great 
attention to taste experiences, managers can make full use of the rich forest resources in forest towns and develop local seasonal forest foods that will arouse tourists' satisfaction and pleasure in taste, smell and other senses.

Third, managers should pay attention to the influence of tourists' basic feelings on their advanced cognition. Digging deep into the connotation of forest culture and establishing the connection between the natural landscape and cultural landscape in forest towns can make tourists have a high-level sensory experience, thus producing a positive tourism experience.

\subsection{Research Limitations and Prospects}

In this study, only 385 tourists from forest towns in Fujian, Guangdong and Sichuan were selected for investigation, which gave certain limitations. Firstly, future research could include 2-3 more forest towns, increase the number of samples, and improve the popularization of the research results. Secondly, the tourism experience is not only influenced by external environment stimulation, but also by tourists' personal characteristics, such as physical characteristics, cultural background, emotional state, self-identity, memory and so on [83]. This study has not yet investigated the tourism motivation of forest town tourists, which is also a deficiency. Future research can further explore the regulatory variables that affect tourists' sensory experience, such as tourism motivation. Understanding the difference of sensory experience of tourists with different motives is helpful when designing the sensory landscape of forest towns, and then to improve the perceived quality of tourist experiences. Finally, it would be helpful to determine how much below the threshold the tourists' five senses stimulation can be before it will destroy the quality of the tourism experience. This is a topic worth exploring.

Author Contributions: D.L. and M.S. contributed to the conception and design of the study; M.S. contributed to analysed data and writing; D.L. contributed to project administration. Both authors have read and agreed to the published version of the manuscript.

Funding: This research received no external funding.

Institutional Review Board Statement: This research does not involve ethical issues and personal privacy and does not require formal ethics approval.

Informed Consent Statement: Informed consent was obtained from all subjects involved in the study.

Data Availability Statement: Not applicable.

Conflicts of Interest: The author declares no conflict of interest.

\section{References}

1. Niu, J.P.; Zhao, T. Analysis on the path of forest town construction. For. Econ. 2017, 10, 100-103.

2. Han, W.Y. Countermeasures for the construction of ecotourism forest towns-Taking Wenci forest town in Chaozhou City as an example. China Econ. Rep. 2017, 3, 138-139. (In Chinese)

3. Zhang, J.Z.; Zeng, Y.X.; Zhang, Y.J.; Cheng, B.D. Summarization and analysis of research literature on domestic forest towns. For. Econ. 2019, 12, 37-42. (In Chinese)

4. Wu, M.S. Study on the cultural authenticity perception of the residents of Nanlang Forest Town and their environmentally friendly behaviors. For. Ecol. Sci. 2019, 34, 347-352. (In Chinese)

5. Tan, Z.Y.; Yang, X.M.; Xiang, J.J. Discussion on the construction prospect of tanxi forest characteristic town in Luxi County. Hubei For. Sci. Technol. 2019, 28, 72-74. (In Chinese)

6. Qi, Y.W. Research on the Planning of forest characteristic towns. For. Prod. Ind. 2019, 11, 68-70. (In Chinese)

7. Huang, J.Y.; Chen, W.X.; Lu, D.M. Study on the characteristic development path of underdeveloped towns in Guangdong mountainous area. For. Econ. Issues 2019, 39, 474-481. (In Chinese)

8. Stamboulis, Y.; Skayannis, P. Innovation strategies and technology for experience-based tourism. Tour. Manag. 2003, 24, 35-43. [CrossRef]

9. Poon, A. The 'new tourism' revolution. Tour. Manag. 1994, 15, 91-92. [CrossRef]

10. Meacci, L.; Liberatore, G. A senses-based model for experiential tourism. Tour. Manag. Stud. 2018, 14, 7-14. [CrossRef]

11. Li, Y.; Gao, X.H.; Huang, J.X.; Wu, M. Analysis of tourists' visual behavior based on photography and eye movement experimentTaking Xiamen university as an example. J. Tour. 2020, 35, 41-52. (In Chinese) 
12. Li, G.S.; Zhang, H.Z.; Lu, L.; Chen, J.Q. A study on the perception process of destination image influenced by tourism promotional films-An experimental exploration of the bali case. Hum. Geogr. 2019, 34, 146-152. (In Chinese)

13. Xu, H.J.; Lu, X.Y. Sound branding: A study on the influence of destination songs on tourists' perceived image. Tour. Sci. 2019, 6,1-16. (In Chinese)

14. Xing, F.P. An analysis of the hierarchy of the "five senses" in Western culture-Taking classical and medieval works as examples Beijing Soc. Sci. 2017, 2, 64-71. (In Chinese)

15. Liu, A.L.; Liu, F.C.; Liu, M.; Deng, Z.Y. Research progress on soundscape of tourism at home and abroad. J. Tour. 2016, 31, 114-126. (In Chinese)

16. Xie, Y.J.; Fan, Y.M. Tourism experience from the perspective of the body-Based on the grounded theory analysis of trekking travel notes and interviews. Hum. Geogr. 2017, 4, 129-137. (In Chinese)

17. Lv, X.Y.; Li, C.X.; McCabe, S. Expanding theory of tourists destination loyalty: The role of sensory impressions. Tour. Manag. 2020, 77, 1-12. [CrossRef]

18. Mateiro, B.; Kastenholz, E.; Breda, Z. The sensory dimension of the tourist experience in mountain destinations: The case of Serra da Estrela Natural Park. Rev. Tur. Desenvolv. 2017, 1, 2027-2038.

19. Xiong, J.; Hashim, N.H.; Murphy, J. Multisensory image as a component of destination image. Tour. Manag. Perspect. 2015, 14, 34-41. [CrossRef]

20. Agapito, D.; Valle, P.; Mendes, J. The sensory dimension of tourist experiences: Capturing meaningful sensory-informed themes in Southwest Portugal. Tour. Manag. 2014, 42, 224-237. [CrossRef]

21. Lv, X.Y.; Li, C.X.; Li, H.F. Sensory impression: The gain of tourist loyalty. J. Tour. 2019, 34, 47-59. (In Chinese)

22. Quan, S.; Wang, N. Towards a structural model of the tourist experience: An illustration from food experiences in tourism. Tour. Manag. 2004, 25, 297-305. [CrossRef]

23. Boorstin. The Image: A Guide to Pseudo-Events in American; Vintage Books Edition: New York, NY, USA, 1961.

24. MacCannell, D. Staged authenticity: Arrangements of social space in tourist settings. Am. J. Sociol. 1973, 79, 589-603. [CrossRef]

25. Cohen, E.A. Phenomenology of tourist experiences. Sociology 1979, 13, 179-201. [CrossRef]

26. Xie, Y.J. Basic Tourism; Nankai University Press: Tianjin, China, 2017. (In Chinese)

27. Xie, Y.J.; Yu, J.; Guo, F.F. Discourse analysis of guestbook: Writing and confession of Tibet tourism experience. Tour. Sci. 2019, 33, 1-20. (In Chinese)

28. Ma, T.; Xie, Y.J. The social construction of tourism experience: A systematic analysis. J. Tour. 2015, 30, 96-106. (In Chinese)

29. Fan, Y.M.; Xie, Y.J. A new probe into the connotation of "experience" and the attributes of tourism experience. J. Tour. 2017, 32, 16-25. (In Chinese)

30. Fan, Y.M. The progress and prospects of research on embodied tourism experience. J. Tour. 2020, 1, 1-19. (In Chinese)

31. Wu, J.; Tang, D.J. A new perspective of tourism experience research: Embodied theory. J. Tour. 2018, 33, 118-125. (In Chinese)

32. Urry, J. The Tourist Gaze: Leisure and Travel in Contemporary; Sage: London, UK, 2000.

33. Urry, J. The Tourist Gaze, 2nd ed.; Sage: London, UK, 2002.

34. Li, L.Y. Tourism gaze: Reflection and reconstruction. J. Tour. 2015, 30, 118-126. (In Chinese)

35. Schmitt, B.H. Experiential marketing. J. Mark. Manag. 1999, 15, 53-67. [CrossRef]

36. Krishna, A.; Schwarz, N. Sensory marketing, embodiment, and grounded cognition: A review and introduction. J. Consum. Psychol. 2014, 24, 159-168. [CrossRef]

37. Agapito, D.; Mendes, J.; Valle, P. Exploring the conceptualization of the sensory dimension of tourist experiences. Tour. Manag. 2013, 11, 62-73. [CrossRef]

38. Agapito, D.; Chung-Shing, C.A. multisensory approach to responsible management in community-based tourism: A case study in Hong Kong. J. Tour. Q. 2019, 1, 1-13.

39. Agapito, D.; Pinto, P.; Mendes, J. Sensory marketing and tourist experiences. Spat. Organ. Dyn. 2012, 10, 7-19.

40. Pan, S.; Ryan, C. Tourism sense-making: The role of the senses and travel journalism. J. Travel Tour. Mark. 2009, 26, 625-639. [CrossRef]

41. Oliver, R.L. Whence consumer loyalty? J. Mark. 1999, 63, 33-44. [CrossRef]

42. Krishna, A. An integrative review of sensory marketing: Engaging the senses to affect perception, judgment and behavior. J. Consum. Psychol. 2012, 22, 332-351. [CrossRef]

43. Ramseook-Munhurrun, P.; Seebaluck, V.N.; Naidoo, P. Examining the structural relationships of destination image, perceived value, tourist satisfaction and loyalty: Case of Mauritius. Science 2015, 175, 252-259. [CrossRef]

44. Song, Z.; Su, X.; Li, L.N. The indirect effects of destionation image on destination loyalty intention through tourist satisfaction and perceived value: The bootstrap approach. J. Travel Tour. Mark. 2013, 30, 386-409. [CrossRef]

45. McCabe, S.; Li, C.; Chen, Z. Time for a radical reappraisal of tourist decision making? Toward a new conceptual model. J. Travel Res. 2015, 55, 3-15. [CrossRef]

46. Agapito, D.; Pinto, P.; Mendes, J. Tourists' memories, sensory impressions and loyalty: In loco and post-visit study in Southwest Portugal. Tour. Manag. 2017, 58, 108-118. [CrossRef]

47. Kim, J.; Kerstetter, D.L. Multisensory processing impacts on destination image and willingness to visit. Int. J. Tour. Res. 2014, 18, 52-61. [CrossRef] 
48. Ghosh, T.; Sarkar, A. "To feel a place of heaven": Examining the role of sensory reference cues and capacity for imagination in destination marketing. J. Travel Tour. Mark. 2015, 33, 25-37. [CrossRef]

49. Chang, R.C.Y.; Kivela, J.; Mak, A.H.N. Attributes that influence the evaluation of travel dining experience: When East meets West. Tour. Manag. 2011, 32, 307-316. [CrossRef]

50. Xie, Y.J. The bipolar emotion model of tourism experience: Happiness-Pain. Res. Financ. Issues 2006, 5, 88-92. (In Chinese)

51. Chen, H.B. Unusual environment and its experience: A re-discussion of the core concepts of tourism. J. Tour. 2017, 32, 22-31. (In Chinese)

52. Sun, X.L.; Lin, B.S.; Gao, J. A review of tourism experience quality evaluation: Research progress, interpretation and prospects of elements. Hum. Geogr. 2018, 1, 143-151. (In Chinese)

53. Sarra, A.; DiZio, S.; Cappucci, M. A quantitative valuation of tourist experience in Lisbon. Ann. Tour. Res. 2015, 53, 1-16. [CrossRef]

54. Bigne, J.; Sanchez, M.I.; Sanchez, J. Tourism image, evaluation variables and after purchase behavior: Inter-relationships. Tour. Manag. 2001, 22, 607-616. [CrossRef]

55. Chen, C.F.; Tsai, D.C. How destination image and evaluative factors affect behavioral intentions? Tour. Manag. 2007, 28, 1115-1122. [CrossRef]

56. Schlesinger, W.; Cervera-Taulet, A.; Pérez-Cabañero, C. Exploring the links between destination attributes, quality of service experience and loyalty in emerging mediterranean destinations. Tour. Manag. Perspect. 2020, 35, 100699. [CrossRef]

57. Kirillova, K.; Fu, X.; Lehto, X.; Cai, L. What makes a destination beautiful? Dimensions of tourist aesthetic judgment. Tour. Manag. 2014, 42, 282-293. [CrossRef]

58. Ding, X. Design of South China sea tourism special train service system based on five senses experience. Packag. Eng. 2017, 38, 24-30. (In Chinese)

59. Luo, C.; Shen, L.; Gao, H. Research on the mechanism of the brand experience of tourist destinations on tourist loyalty. J. Donghua Univ. (Nat. Sci. Ed.) 2016, 5, 752-759. (In Chinese)

60. Jin, N.P.; Lee, S.; Lee, H. The effect of experience quality on perceived value, satisfaction, image and behavioral intention of water park patrons: New versus repeat visitors. Int. J. Tour. Res. 2015, 17, 82-95. [CrossRef]

61. Lv, L.H.; Wang, Y.P. A study on the influence of awe on tourists' behavior intentions in mountainous scenic spots: A case study of Hangzhou Jingshan scenic spot. World Geogr. Res. 2017, 6, 131-142. (In Chinese)

62. Fornell, C.; Johnson, M.D.; Anderson, E.W.; Cha, J.; Bryant, B.E. The American customer satisfaction index: Nature, purpose, and findings. J. Mark. 1996, 60, 7. [CrossRef]

63. Wang, X.; Mei, H. Customer loyalty model and empirical research in tourist destinations. Tour. Trib. 2006, 21, 33-38. (In Chinese)

64. Wen, Z.L.; Ye, B.J. Analysis of mediation effect: Method and model development. Prog. Psychol. Sci. 2014, 22, 731-745. (In Chinese)

65. Liu, A.; Wang, X.L.; Liu, F.; Yao, C.; Deng, Z. Soundscape and its influence on tourist satisfaction. Serv. Ind. J. 2017, 38, 164-181. [CrossRef]

66. Krishna, A.; Lwin, M.O.; Morrin, M. Product scent and memory. J. Consum. Res. 2010, 37, 57-68. [CrossRef]

67. Luan, B.; Chai, M.W.; Wang, X. Research progress on green infrastructure. Acta. Ecol. Sin. 2017, 15, 5246-5261. (In Chinese)

68. Lu, X.Y. Reflections on the sensory marketing of destination image. J. Tour. 2018, 33, 7-8. (In Chinese)

69. Xie, Y.J.; Wu, K. Expectation and feeling: An interactive model of tourism experience quality. Tour. Sci. 2000, 2, 1-4. (In Chinese)

70. Chen, Y.; Zhu, M.Q.; Chen, L.; Su, J.B. Development and design of forest tourism products based on incense culture concept. Issues For. Econ. 2019, 39, 197-203. (In Chinese)

71. Liu, T.; He, M.T. Developing the forest health industry is the inevitable result of the implementation of supply-side structural reforms. For. Econ. 2012, 2, 39-42. (In Chinese)

72. Wu, C.B.; Feng, A.R. Study on Dalian tourism food perception and experience. Resour. Dev. Mark. 2018, 34, 1771-1776. (In Chinese)

73. Kivela, J.; Crotts, J.C. Tourism and gastronomy: Gastronomy's influence on how tourists experience a destination. J. Hosp. Tour. Res. 2006, 30, 354-377. [CrossRef]

74. Zheng, Y.X.; Zhang, Z.G. Analysis of ecological security elements and landscape perception transitivity of forest tourist attractions. J. Cent. South Univ. For. Technol. 2015, 2, 123-129. (In Chinese)

75. Zhong, K.; Wang, H.Z.; Yang, C. Summarization and prospects of destination sensory marketing research. Tour. Guide 2019, 2, 66-92. (In Chinese)

76. Lu, C.B.; Lin, S.J. Research on the motivation of tourists choosing online short-term rental accommodation. Econ. Manag. 2018, 40, 153-167. (In Chinese)

77. Yin, Y.M.; Zheng, X.M. Research on the host-guest interactive experience of shared tourism accommodation-Based on the analysis of interactive ritual chain theory. J. Huaqiao Univ. (Philos. Soc. Sci. Ed.) 2017, 3, 90-98. (In Chinese)

78. Ma, T.; Li, X.; Xie, Y.J. Old wine in new bottle? The myth of tourist satisfaction measurement. J. Tour. 2017, 6, 53-63. (In Chinese)

79. Darcy, S.; Dickson, T. A whole-of-life approach to tourism: The case for accessible tourism experiences. J. Hosp. Tour. Manag. 2009, 16, 32-44. [CrossRef]

80. Michopoulou, E.; Darcy, S.; Ambrose, I.; Buhalis, D. Accessible tourism futures: The world we dream to live in and the opportunities we hope to have. J. Tour. Futures 2015, 1, 179-188. [CrossRef]

81. Cantero, K.N.G. Theoretical analysis on the foundations of sensory-based tourism for the blind. J. Am. Acad. Res. 2018, 6, 120-126. 
82. Zhong, K.; Wang, H.Z.; Yang, C. Review and prospect of sensory marketing research. Foreign Econ. Manag. $2016,38,69-85$. (In Chinese)

83. Cutler, S.Q.; Carmichael, B.A. The Tourism and Leisure Experience: Consumer and Managerial Perspectives-The Dimensions of the Tourist Experience; Channel View Publications: Bristol, UK, 2010. 